\title{
Sodium glycerophosphate in the treatment of neonatal hypophosphataemia
}

\author{
I Costello, C Powell, A F Williams
}

\begin{abstract}
Nineteen very low birthweight (mean (SD) gestational age 28 (3) weeks) were parenterally fed nutrition solutions containing inorganic calcium and phosphorus salts. All infants had hypophosphataemia. Plasma concentrations were maintained between $1.5 \mathrm{mmol} / 1$ and $2.2 \mathrm{mmol} / \mathrm{M}$. Plasma phosphorus concentrations reached 1.5 mmol/l or greater in three patients after 12 hours, in a further nine patients after 36 hours, and in all patients by 60 hours. Changes in plasma calcium concentrations were not significant.

(Arch Dis Child 1995; 73: F44-F45)
\end{abstract}

Keywords: sodium glycerophosphate, hypophosphataemia.

The provision of calcium and phosphorus in parenteral nutrition solutions is limited by the low solubility of inorganic calcium and phosphorus salts. Hypophosphataemia in parenterally fed very low birthweight infants is therefore difficult to treat. ${ }^{1}$

The use of an organic phosphate salt, such as sodium glycerophosphate, allows higher concentrations of calcium and phosphorus to remain in solution without reducing solution $\mathrm{pH} .{ }^{2-5}$ Phosphorus in the form of a metabolisable anion also reduces the contribution made by inorganic phosphorus salts to the net acid concentration of parenteral nutrition regimens.

\section{Method}

The mean (SD) gestational age was 28 (3) weeks. The median birthweight was $0.8 \mathrm{~kg}$ (range $0 \cdot 65-2 \cdot 2 \mathrm{~kg}$ ). The mean postnatal age
Department, St George's Hospital, Blackshaw Road, London SW17 0QT I Costello C Powell

Department of Child Health

A F Williams

Correspondence to:

Costello.

Accepted 15 March 1995 at onset of hypophosphataemia was 6

days.

Nineteen parenterally fed very low birthweight infants with hypophosphataemia (defined as a plasma phosphorus concentration of less than $0.5 \mathrm{mmol} / \mathrm{l}$ ) were studied while all were receiving parenteral nutrition solutions containing inorganic calcium and phosphorus salts at the limits of solubility.

Plasma calcium and inorganic phosphorus concentrations were routinely measured each day in infants receiving parenteral nutrition. If the plasma phosphorus concentration fell below $0.5 \mathrm{mmol} / \mathrm{l}$, sodium glycerophosphate was used as the sole phosphorus source to increase the amount of phosphorus provided in the parenteral nutrition solutions from $0.5-1.0 \mathrm{mmol} / \mathrm{kg} /$ day to $1.5 \mathrm{mmol} / \mathrm{kg} /$ day infused over 24 hours. This also permitted an increase in the amount of calcium infused to $1.5 \mathrm{mmol} / \mathrm{kg} / \mathrm{day}$, supplied as calcium gluconate.

Infants continued to receive the increased amounts of calcium and phosphorus. Plasma concentrations were maintained between 1.5 $\mathrm{mmol} / \mathrm{l}$ and $2 \cdot 2 \mathrm{mmol} / \mathrm{l}$.

Sodium glycerophosphate is supplied as a solution for injection containing $2 \mathrm{mmol} / \mathrm{ml}$ sodium and $1 \mathrm{mmol} / \mathrm{ml}$ of phosphate (KabiPharmacia).

Routine plasma samples were timed as closely as possible to 12,36 , and 60 hours after the addition of the glycerophosphate parenteral nutrition solutions. Calcium and phosphorus concentration were analysed using the phosphate-molybdate complex method for ionised phosphate $\left(\mathrm{PO}_{4}{ }^{2-}\right)$ and the cresolphthalein complexone method for calcium. These methods are used in most hospital biochemistry laboratories for routine measurement of plasma calcium and phosphorus concentrations. Standard solutions of sodium glycerophosphate and parenteral nutrition containing glycerophosphate were also analysed to exclude interference with the assay procedure for plasma inorganic phosphate.

The standard solutions of glycerophosphate did not interfere with the assay procedure for inorganic plasma phosphate, indicating that all measured plasma phosphate was inorganic.

\section{STATISTICAL ANALYSIS}

The paired two tailed Student's $t$ test was used to determine the significance of differences in the mean plasma concentrations of calcium and phosphate before and during the infusion of sodium glycerophosphate.

Change in plasma phosphorus and calcium concentration after initiation of glycerophosphate supplemented parenteral nutrition. Mean (SD) plasma calcium $(\diamond)$ and phosphorus $(\mathbf{\Delta})$ are shown on the ordinate as mmoll. 
Results

The mean (SD) increases in plasma phosphorus concentration from baseline at 12,36 , and 60 hours after initiation of glycerophosphate supplemented parenteral nutrition were $0.33(0.08), 0.72(0.3)$, and $0.90(0.3) \mathrm{mmol} / \mathrm{h}$, respectively; $\mathrm{P}<0.0001$ (figure).

The corresponding changes in plasma calcium concentration were $0.02(0.22) \mathrm{mmol}$, $-0.23(0.23) \mathrm{mmol}$, and $-0.17(0.26) \mathrm{mmol}$, respectively. These changes were not significant.

Plasma phosphorus concentrations reached $1.5 \mathrm{mmol} / \mathrm{l}$ or greater in three patients after 12 hours, in a further nine patients after 36 hours, and in all patients by 60 hours. No adverse effects were noted.

\section{Discussion}

Use of sodium glycerophosphate allowed greater concentrations of calcium and phosphorus to be administered via parenteral nutrition solutions. This uncontrolled study indicated that administration of phosphorus as sodium glycerophosphate $(1.5 \mathrm{mmol} / \mathrm{kg} /$ day $)$ was associated with a significant increase in plasma phosphate concentrations.

The mechanism of the observed effect on plasma phosphate is unclear. Either phosphate from infused glycerophosphate is directly available or phosphorus is displaced from the intracellular phosphate pool.
Glycerophosphate is metabolised by plasma alkaline phosphatase, releasing phosphate and glycerol. As alkaline phosphatase is present and active in neonatal plasma, we propose that phosphate is derived from the glycerophosphate molecule itself. Glycerol is presumably rephosphorylated in the liver by glycerol kinase and utilised in glycolytic or gluconeogenic pathways.

Hanning et $\mathrm{al}^{6}$ have shown that conventional doses of organic and inorganic calcium and phosphorus salts in parenteral nutrition solutions achieve similar mineral retention rates in neonates, but further work is required to determine the effects of delivering increased amounts of phosphorus as sodium glycerophosphate, such as those used in our study, on bone mineral accretion.

1 Bishop N. Bone disease in preterm infants. Arch Dis Child 1989; 64: 1403-9.

2 MacMahon P, Mayne PD, Blair M, Pope C, Kovar IZ. Calcium and phosphate solubility in neonatal intravenous feeding solutions. Arch Dis Child 1990; 65: 352-3.

3 Niermeyer S, Thieme R, Gwan G, Thibodeau S, Quissel BJ. Optimised calcium/phosphorus solubility in a parenteral nutrition solution containing dicarboxylic amino acids and cysteine. $\mathcal{F}$ Am Coll Nutr 1986; 5: 459-66.

4 Laine, L, Shulman RJ, Pitre D, Lifschitz CH, Adams J. Cysteine usage increases the need for acetate in neonates who receive total parenteral need for acetate in neonates who receive total

5 Raupp P, Kries RV, Pfahl HG, Menz F. Glycero vs glucose phosphate in parenteral nutrition of premature infants: $A$ comparative in vitro evaluation of calcium/phosphorus compatibility. F Parent Ent Nutr 1991; 15: 469-73.

6 Hanning RM, Atkinson SA, Whyte RK. Efficacy of calcium glycerophosphate vs conventional mineral salts for tota parenteral nutrition in low birthweight infants: a randomised clinical trial. Am $\mathcal{F}$ Clin Nutr 1991; 54: 903-8. 